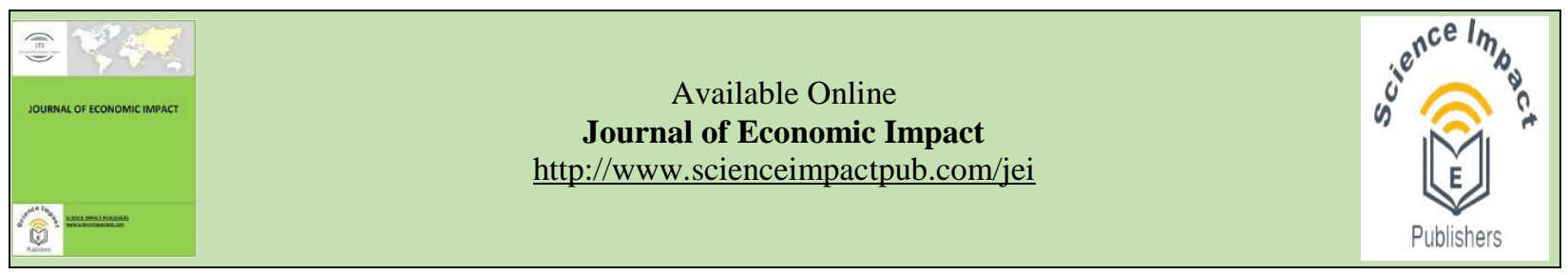

\title{
TRENDS IN CEREAL PRODUCTION AND YIELD DYNAMICS IN SUB-SAHARAN AFRICA BETWEEN 1990-2015
}

\author{
Richard A Nyiawung a, Neville Suh ${ }^{\mathrm{b}}$ and Ghose Bishwajit ${ }^{\mathrm{a}, *}$ \\ a School of International Development and Global Studies, University of Ottawa, Ottawa, Ontario, Canada \\ b Department of Agricultural Economic and Agribusiness, University of Buea, Buea, Cameroon
}

\section{HIGHLIGHTS}

- The study reveals that 33 (75\%) of countries in SSA have experienced an expansion in land under cereal production while $11(25 \%)$ of countries have reduced land under cereal production with an average increase of 679,664 hectares.

- About, 32 (73\%) of countries have experienced an increase in cereal yield, while 12 (27\%) of countries have experienced a reduction in cereal yield, averaging to $311 \mathrm{~kg}$ per hectare in SSA.

- The study also shows that $35(80 \%)$ of countries have experienced an increase in cereal production while 9 $(20 \%)$ of countries have experienced a reduction in cereal production with a total of $1635201 \mathrm{~kg}$ per hectare in SSA.

- Overall, about $71 \%$ of the countries in SSA are experiencing a continuous increase in cereal production, yield levels and land area under cereal production, while about $29 \%$ are experiencing a reduction in cereal yield, production levels and land area under cereal production.

- However, SSA still has the lowest yield growth rate with the highest number of food-insecure persons ( $35.5 \%$ of its population), which is forecast to exacerbate further given the continuous population increase.

\section{ABSTRACT}

Cereal serves as a very important and vital staple food for many smallholder farming communities in Sub-Saharan Africa (SSA). In this paper, we examined changes in land under cereal production; changes in cereal yield; and changes in cereal production between 1990 and 2015 in Sub-Sahara Africa (SSA). The paper looks at the threats and potential of cereal production with respects to how it helps to address issues of food security and improvements needed to enhance and promote production in the region. The study reveals that $33(75 \%)$ of countries in SSA have experienced an expansion in land under cereal production while $11(25 \%)$ of countries have reduced land under cereal production with an average increase of 679,664 hectares. Further, 32 (73\%) of countries have experienced an increase in cereal yield, while $12(27 \%)$ of countries have experienced a reduction in cereal yield, averaging to $311 \mathrm{~kg}$ per hectare in SSA. The study also shows that $35(80 \%)$ of countries have experienced an increase in cereal production while $9(20 \%)$ of countries have experienced a reduction in cereal production with a total of $1635201 \mathrm{~kg}$ per hectare in SSA. Overall, about $71 \%$ of the countries in SSA are experiencing a continuous increase in cereal production, yield levels and land area under cereal production, while about $29 \%$ are experiencing a reduction in cereal yield, production levels and land area under cereal production. However, SSA still has the lowest yield growth rate with the highest number of food-insecure persons (35.5\% of its population), which is forecast to exacerbate further given the continuous population increase. Hence, it is essential to step up cereal production from the current attainable levels to an actual or reasonable and scalable level through innovative research, training, and technological advancement and production capabilities in the region.

Keywords: Cereal production; land cover; cereal yield; Sub-Sahara Africa.

Received: Oct 15, 2019; Accepted: Dec 29, 2019; Published: Dec 30, 2019.

* Correspondence: School of International Development and Global Studies, University of Ottawa, Ottawa, Ontario, Canada Email: brammaputram@gmail.com

\section{Introduction}

Agriculture is vital in supporting sustainable rural livelihoods and economic growth for most of Africa's growing population. Between $20-30 \%$ of GDP and
$55 \%$ of the total value of African exports come from the agricultural sector (World Bank, 2008). However, there has been a decreased trend in per capita food 
production in Africa over the years. Between 1970 and 2007, there was a reduction of $30 \%$ in per capita food production in Eastern Africa, 20\% in Southern Africa, $2 \%$ in Western Africa, and $40 \%$ in Central Africa (USDA, 2010). In comparison, per capita, food production increased by $35 \%$ in South Asia (Lal, 2015). Moreover, it is worth noting that over $70 \%$ of the inhabitants in Sub-Sahara Africa (SSA) live in rural areas, with about $85 \%$ of their livelihoods dependent on rain-fed subsistence agriculture (Shah et al., 2008). In Africa alone, more than 218 million people (about $30 \%$ of its population) live in situations of acute malnutrition and hunger (FAO, 2010). Given the efforts put in place by agricultural researchers and development organizations in the past 40 years, this has paved the way for improving production and yield levels, decreasing poverty and improving food security in the SSA region. However, progress has not been experienced all over SSA and has not been very spontaneous to recent technological advancements in the area (Spielman \& Pandya-Lorch, 2009). It is forecast that SSA is one of the regions in the world highly dependent on cereal imports and its cereal selfsufficiency will continue to fall further from $59 \%$ in 2006/08 to $54 \%$ by 2050 (FAO, 2010). With such a scenario, food security is threatened. SSA is still the most extensive food-insecure region in the world posing a threat to $35.5 \%$ of its population, and it is projected that, by $2028,24 \%$ of its people will still be food insecure (Thome et al., 2018).

Population growth and urbanization remain a threat to food security in the region with most of its cities growing at a rate of 3-4.5\% (Lal, 2015). It was also estimated that one in four (or 240 million) of inhabitants in this region were vulnerable and food insecure in 2010 (FAO, WFP \& IFAD, 2012). The vulnerability of the region to climate-induced shocks and risk often results in crop stress and significant yield losses which puts many of its smallholder farmers and their families at risk (Tongruksawattana $\&$ Wainaina, 2019). Population growth remains on the rise with an exponential increase of 800 million in 2000 to 1.1 billion in 2020 and a projected 1.8 billion by 2050 (UNDESA, 2013). In the year 2000, SSA had 800 million people and is expected to have 1.1 billion inhabitants by $2020,1.8$ by $2050,2.3$ by 2100 , and to stabilize at around 2.1 billion in 2150 (Van Oort et al., 2015). This rapid population growth exacerbates food insecurity issues in the region if measures are not taken to address key food insecurity challenges. Producing sufficient staple food crops is a major challenge in sub-Saharan Africa (Boyd et al., 2013). Increasing crop yield stability is a crucial goal shared by farmers, breeders and consumers working together in addressing some of these challenges. Maximum yield potentials can be realized if farmers have access and knowledge to use, among other farm inputs such as fertilizers, pesticides, water, seeds, and land irrigation facilities. Ironically, hunger and malnutrition continue to threaten SSA even though the region has an abundant agricultural and natural endowment, thus necessitating advanced and improved technology for producers (Collier \& Dercon, 2014). Undeniably, growth in the agricultural sector has been earmarked as the best option to propoor and long-term economic growth in SSA (Diao, et al., 2010; Jayne \& Rashid, 2013). The importance of a vibrant and viable economy has led to the formulation of policies for a Green Revolution in Africa and is currently being supported by donors like the African Development Bank and the World Food Program (Ward et al., 2013; Sanchez et al., 2009). Despite the high dependence on agriculture, there has been a steady decrease in productivity in SSA over the last 50 years (Dinar et al., 2012). Indeed, SSA's agriculture has experienced the slowest record of productivity increase in the world (Sinclair \& Rufty, 2012).

Major production constraints in SSA are declining soil quality, low water, and nutrients for different cropping systems (Conway \& Schipper, 2011). About $97 \%$ of land under cultivation in SSA relies on rainfall and is susceptible to high seasonal rainfall variability and drought threats (McIntyre, 2009). Cereal yields vary with the amount of rain during the growing season and with the amount received at the critical flowering stage of the crop. With the severe periodic droughts in SSA, only a small proportion of the land is irrigated or that which can be equipped with irrigation facilities (Lal, 2015). Irrigation technology is very limited in SSA with just $4 \%$ of the area under production, compared with $29 \%$ in East Asia and $39 \%$ in South Asia (World Bank, 2008). Cereal yield in Africa is 2.5 times below that of the developing world average and increased agricultural productivity could provide dramatic benefits (FAO, 2010). Underproduction caused by lack of technology and the extensive extractive farming activities carried out in SSA associated with low farm inputs is a primary cause of the huge gap between the attainable and actual crop yields (Lal, 2015). Subsequent demands for cereals in SSA may have to be met even under conditions of prevailing or decreasing land area. In SSA, this will entail massive investment in infrastructural development and agricultural research and technology (Baulcombe et al., 2009). This will require restoring of degraded soils, increased farm input supplies, increased water availability and environmental improvements (Lal, 2015). Hence, a better strategy must be a sustainable intensification of their food systems as defined by some to be "producing more food from the same area of land while reducing its environmental impact" (Bourne, 2019). 


\section{Methodology}

Data for the study was sourced from the world development indicators (WDI) of the World Bank database, collated and analyzed statistically using $\mathrm{R}$ studio statistical package. Country-wise percentages of cereal yield were shown using bar plots. All charts were prepared with $\mathrm{R}$ studio. This paper specifically examines changes in land under cereal production; changes in cereal yield; and changes in cereal production for 1990-2015 in SSA. The paper advances a qualitative discourse and understanding of the dynamics in cereal production and yield gaps in SSA which can serve as an essential guide and information for policymakers and researchers who want to formulate and implement measures aimed at improving cereal production levels in SSA to levels that can address some of the food security challenges for its growing population.

\section{Results}

Land under Cereal Production: Current cereal crop dynamics (changes in cultivated area, production, and yield) in SSA are based on World Bank data throughout 1990-2015. Figure 1 shows that in 1990 Nigeria and Niger devoted more land to cereal production with 1540000 and 6882262 hectares of land, respectively. In the same year, Mauritius had the lowest land under cereal production with 545 hectares. Figure 2 shows that in 2015, Nigeria and Ethiopia were using more land for cereal production, 1763152 and 9974316 hectares, respectively. Mauritius still had the smallest land under cereal production with 411 hectares. The average land area devoted to cereal production in SSA increased from 1522946 hectares in the year 1990 to 2202610 hectares in the year 2015 .

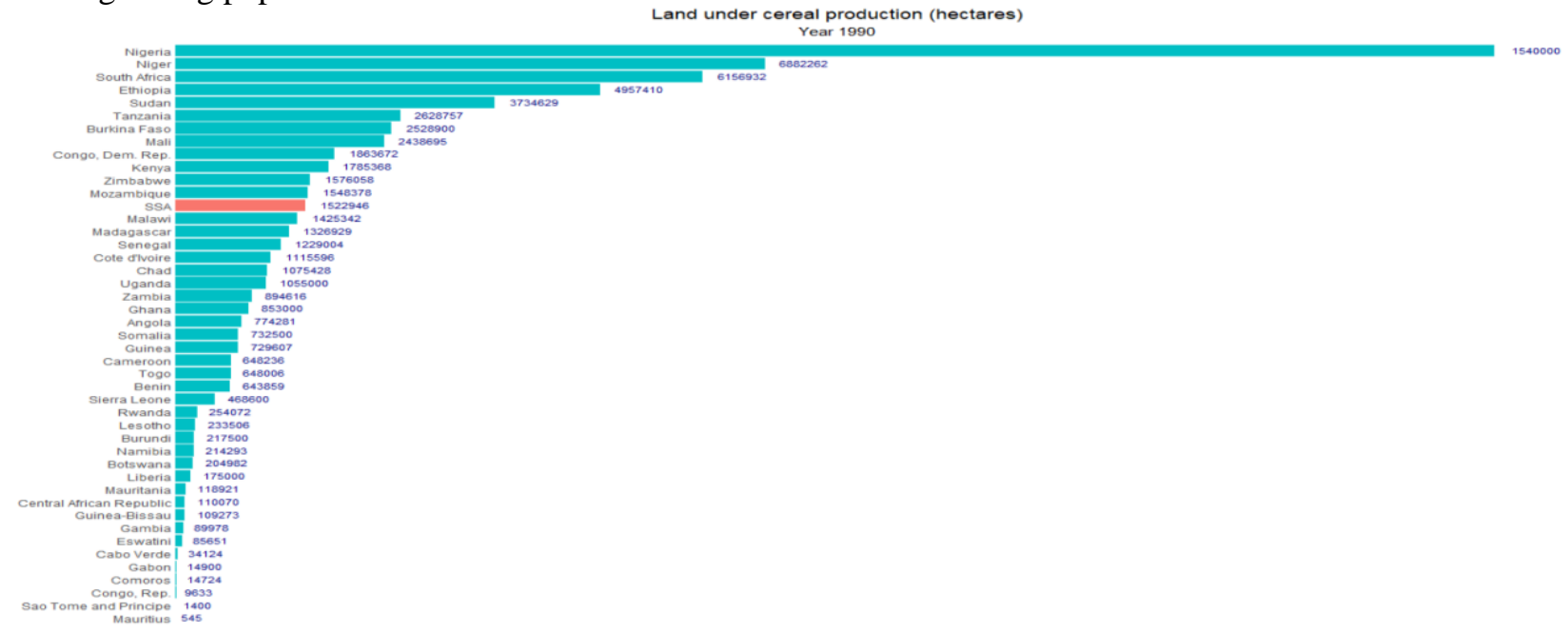

Figure 1: Land under Cereal Production (Hectares) in SSA in 1990

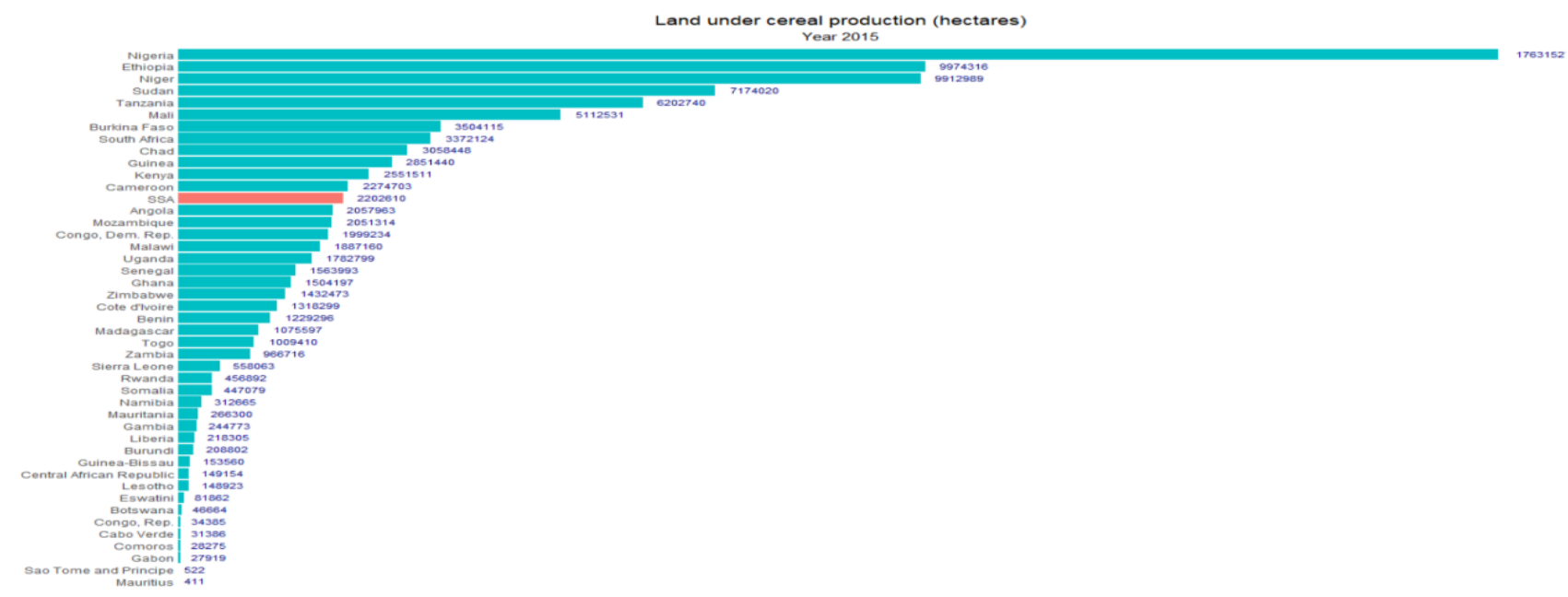

Figure 2: Land under Cereal Production (Hectares) for SSA in 2015 
Changes in Land under Cereal Production: Figure 3 shows how Ethiopia and Tanzania have undergone the most significant positive changes in land area under cereal production with 5016906 and 3573983 hectares respectively, while South Africa and Somalia have progressively decreased the total land area devoted to cereal production with -2784808 and -285421 hectares respectively. Overall, 33 countries have experienced an expansion in land under cereal production while 11 countries have reduced land area under cereal production with a positive average increase of $679664(14 \%)$ hectares in SSA.

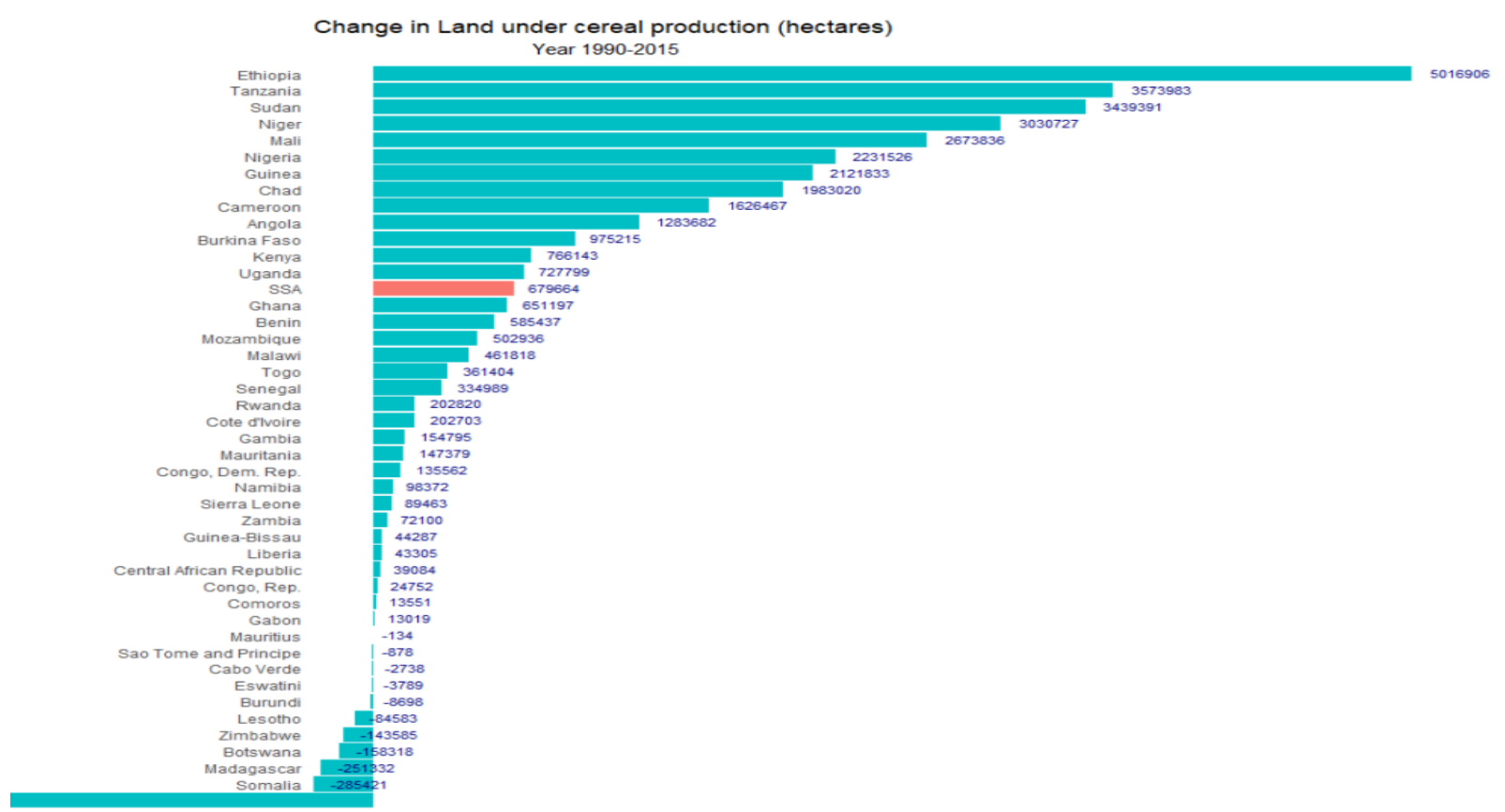

Figure 3: Changes in Land under Cereal Production (Hectares) for SSA: 1990-2015

Cereal Yield: Figure 4 shows that Mauritius and Madagascar had the highest cereal yield, 4191 and 1945 in kilograms per hectare, respectively in the year 1990. Niger and Botswana had the lowest yield of 310 and 266 in kilograms per hectare respectively, which is far below the average yield of 1109 kilograms per hectare in SSA in the year 1990. Figure 5 depicts that, Madagascar and South Africa had the highest cereal yield, 3773 and 3537 in kilograms per hectare, respectively in the year 2015. Namibia and Cabo Verde had the lowest yield of 395 and 277 in kilograms per hectare respectively, which is far below the average yield of 1420 in kilograms per hectare in SSA in the year 2015. The average cereal yield in SSA increased from 1109 kilograms per hectare in the year 1990 to 1420 kilograms per hectare in the year 2015 .

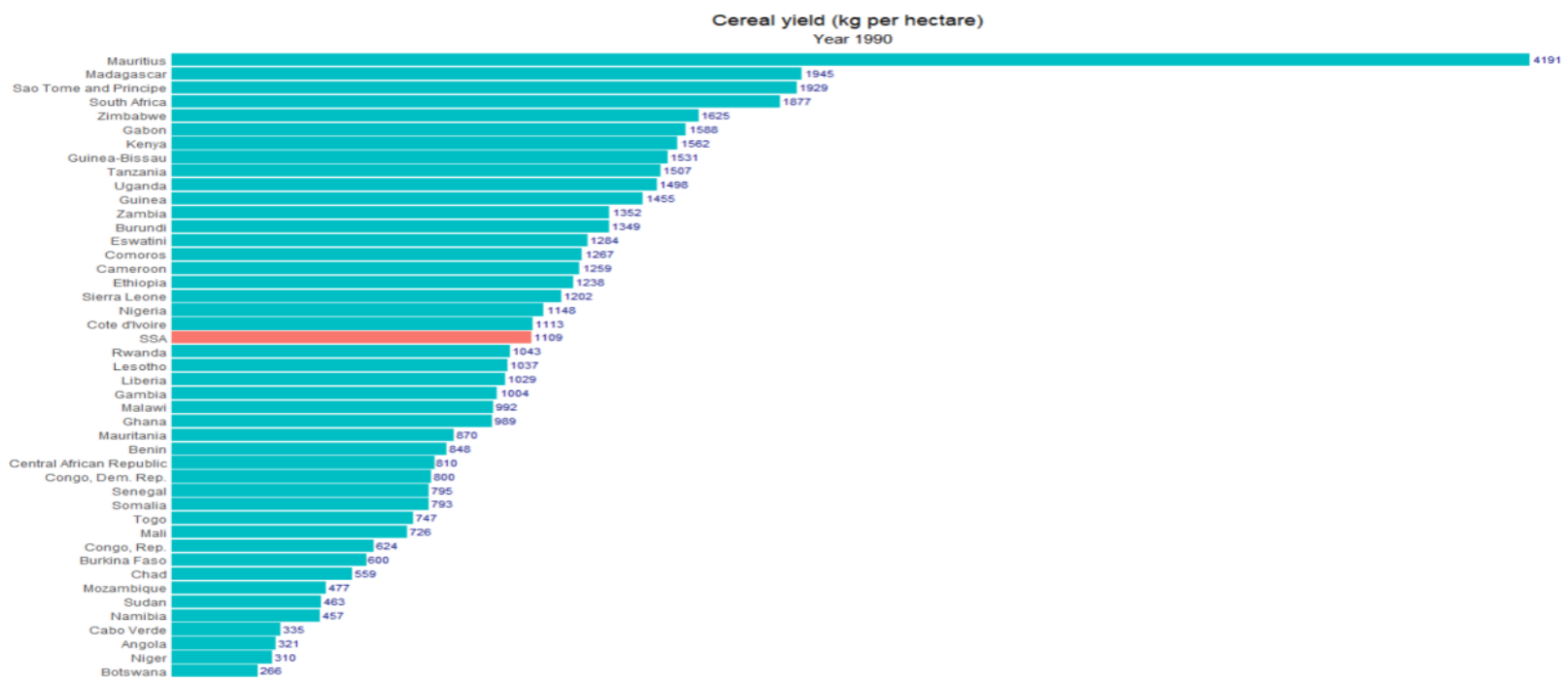


Figure 4: Cereal Yield in kg per Hectare for SSA in 1990

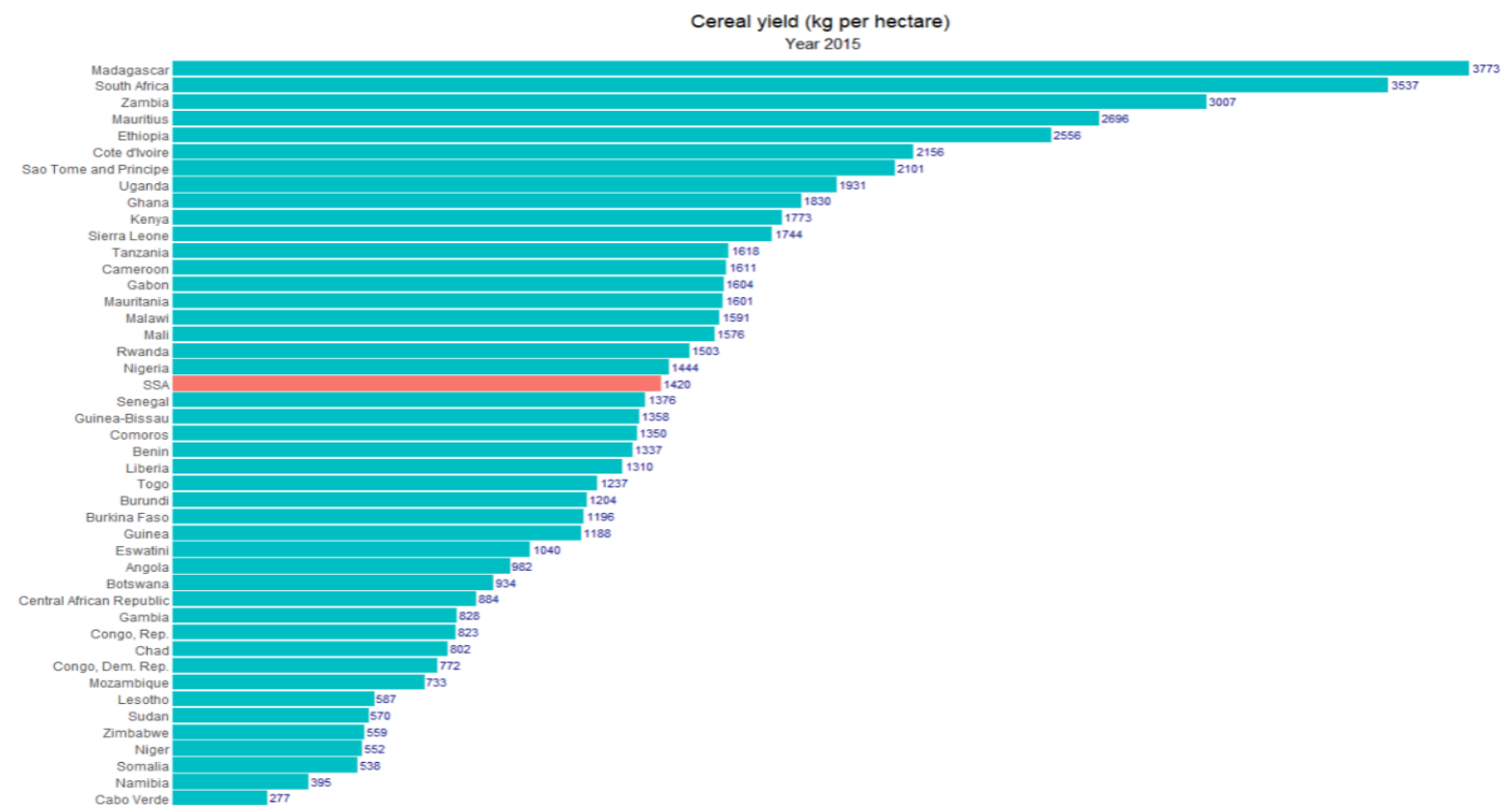

Figure 5: Cereal Yield in kg per Hectare for SSA in 2015

Changes in Cereal Yield: Figure 5 shows changes in cereal yield in the years 1990 and 2015. Madagascar and South Africa have experienced the most significant positive changes in cereal yield with 1828 and $1660 \mathrm{~kg}$ per hectare, respectively. Mauritius and Zimbabwe have experienced the highest reduction in cereal yield over the years with -195 and $-1066 \mathrm{~kg}$ per hectare, respectively. Overall, 32 countries have experienced an expansion in cereal yield while 12 countries have experienced a reduction in cereal yield with a positive average increase of $311 \mathrm{~kg}$ per hectare $(17 \%)$ in SSA.

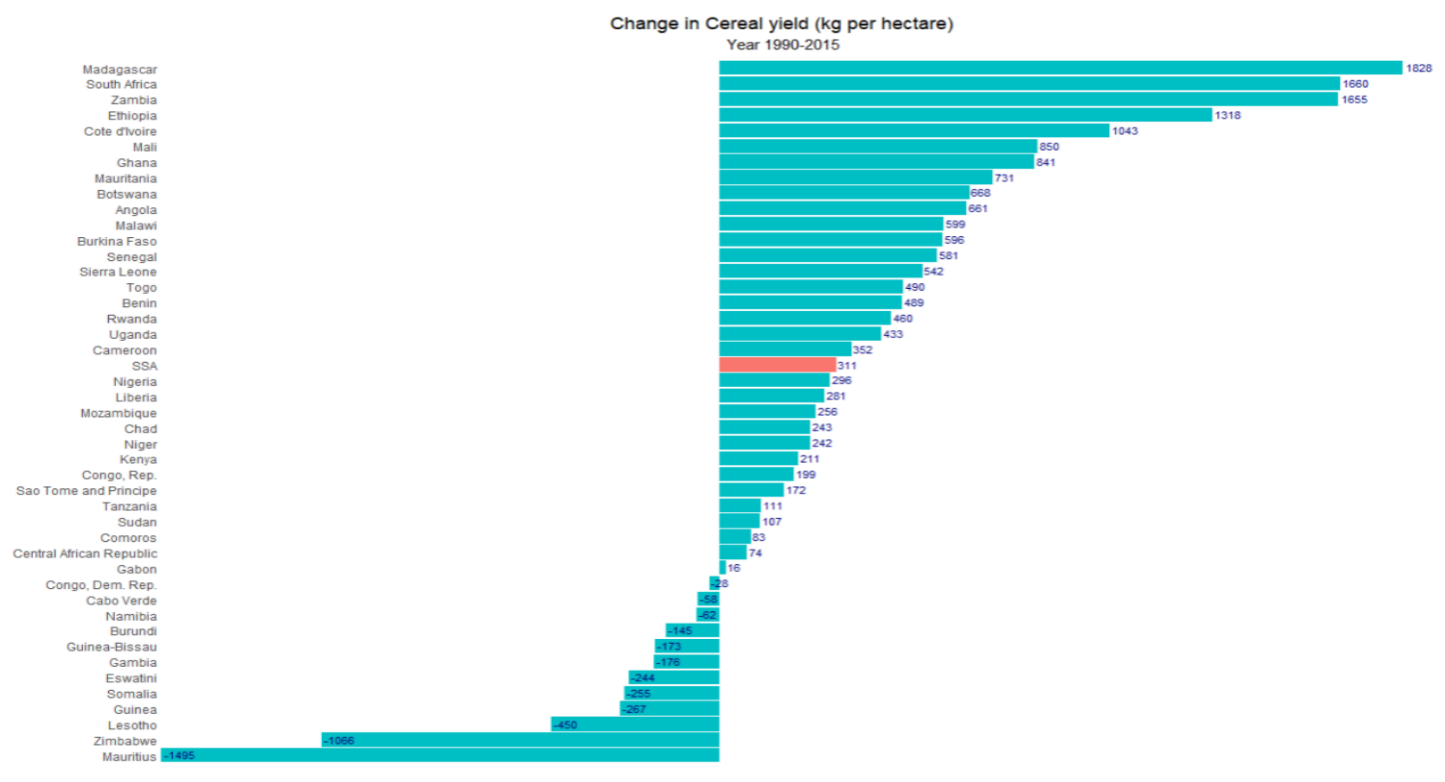

Figure 6: Changes in Cereal Yield in kg per Hectare for SSA: 1990-2015

Cereal Production: Figures 7 and 8 show cereal production in metric tons. Nigeria and South Africa were the two leading producers of cereal with 17678000 and 11558395 metric tons respectively in the year 1990. Mauritius and Sao Tome had the lowest production of 2284 and 2700 metric tons respectively, which is far below the average output of 1603912 metric tons in SSA in the year 1990. Ethiopia and 
Nigeria were the two largest producers of cereal in the year 2015 with 25495127 and 25451082 metric tons, respectively. Sao Tome and Mauritius were the least producers with 1096 and 1108, respectively, and this is far below the average production level of 3239113

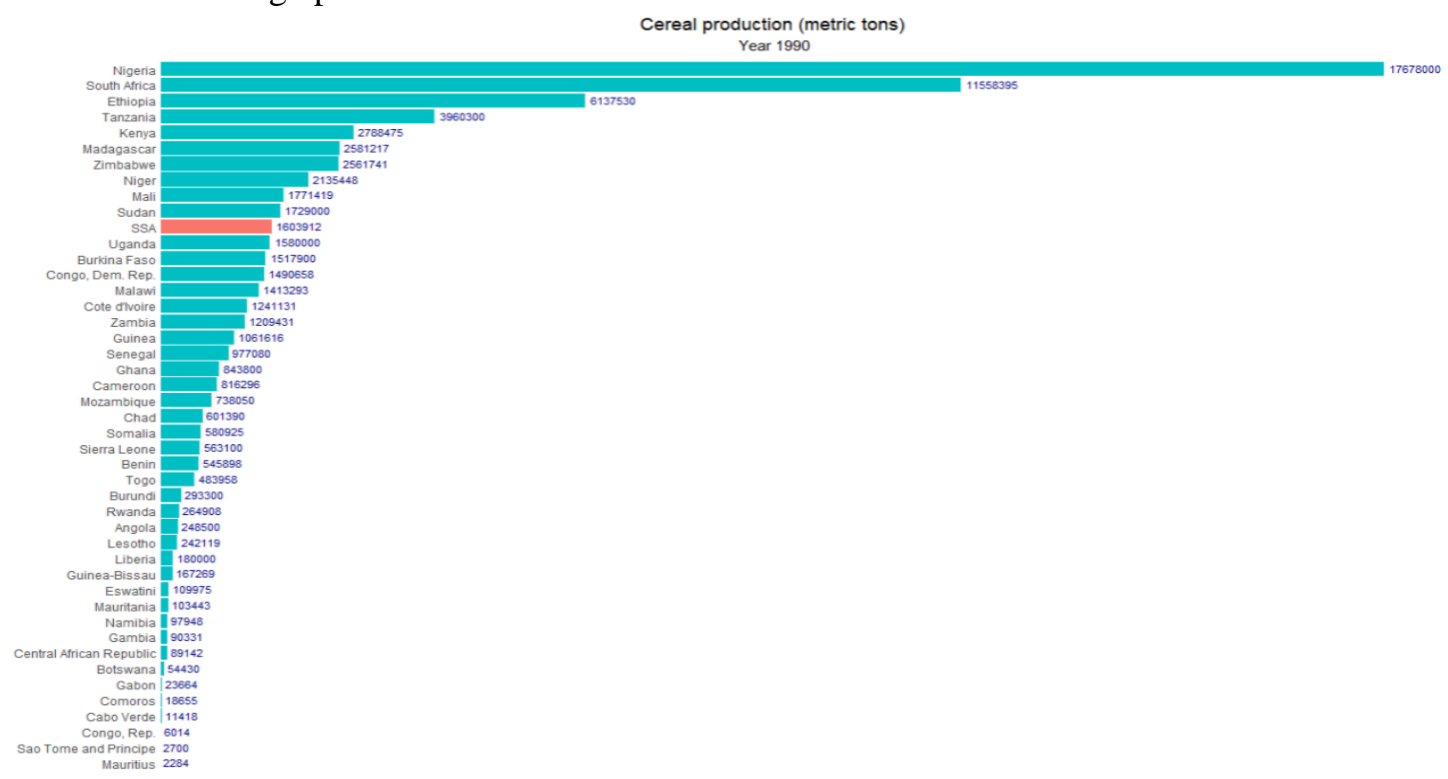

Figure 7: Cereal Production in Metric Tons for SSA in 1990

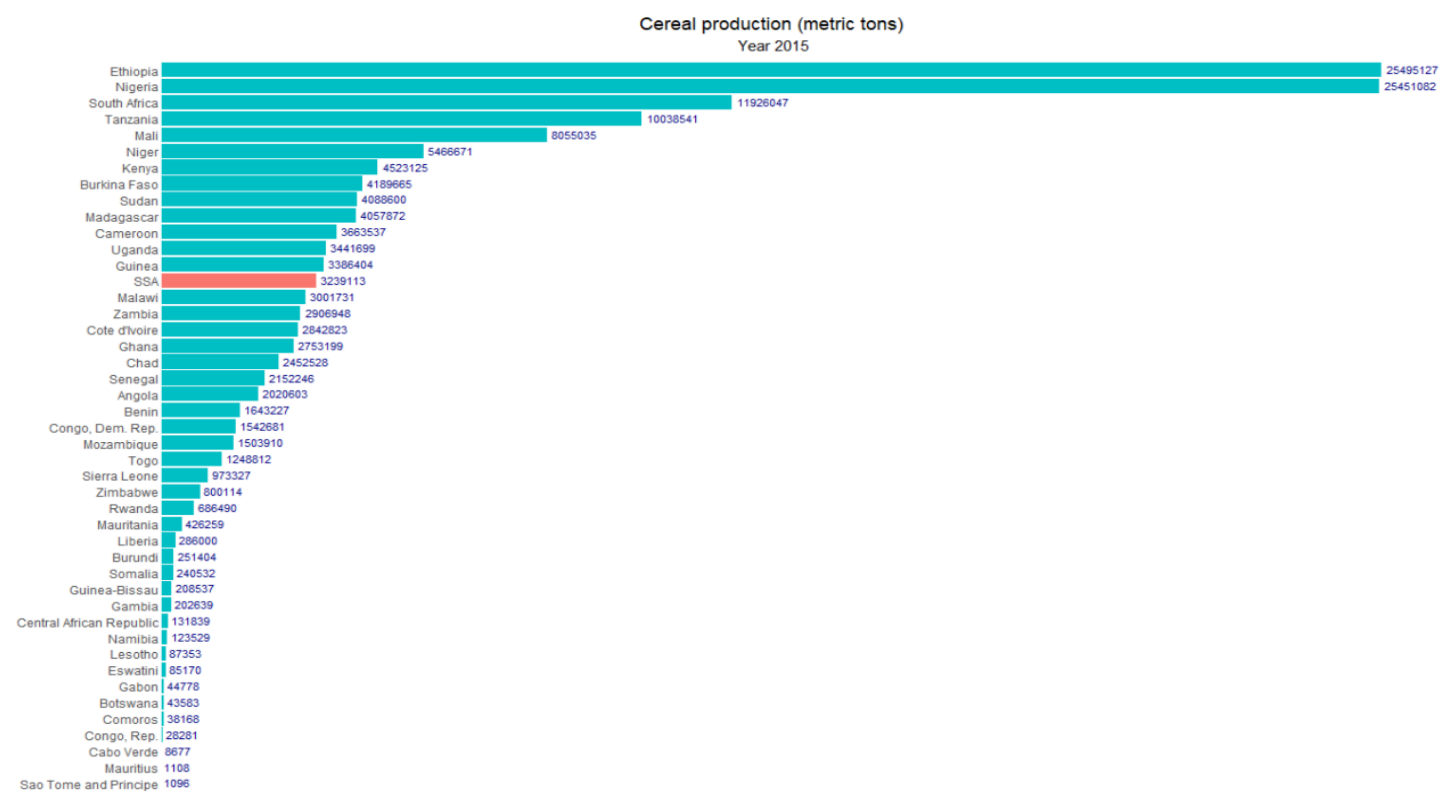

Figure 8: Cereal Production in Metric Tons for SSA in 2015

Changes in Cereal Production: Figure 9 shows changes in cereal production in the years 1990 and 2015. Ethiopia and Nigeria have undergone the most significant positive changes in cereal production with production levels at 19357597 and 77773082 metric tons, respectively. Somalia and Zimbabwe have experienced the least changes in cereal production metric tons in SSA in the year 2015. The average cereal production in SSA increased by $4 \%$ from 1603912 metric tons in the year 1990 to 3239113 metric tons in the year 2015 . 


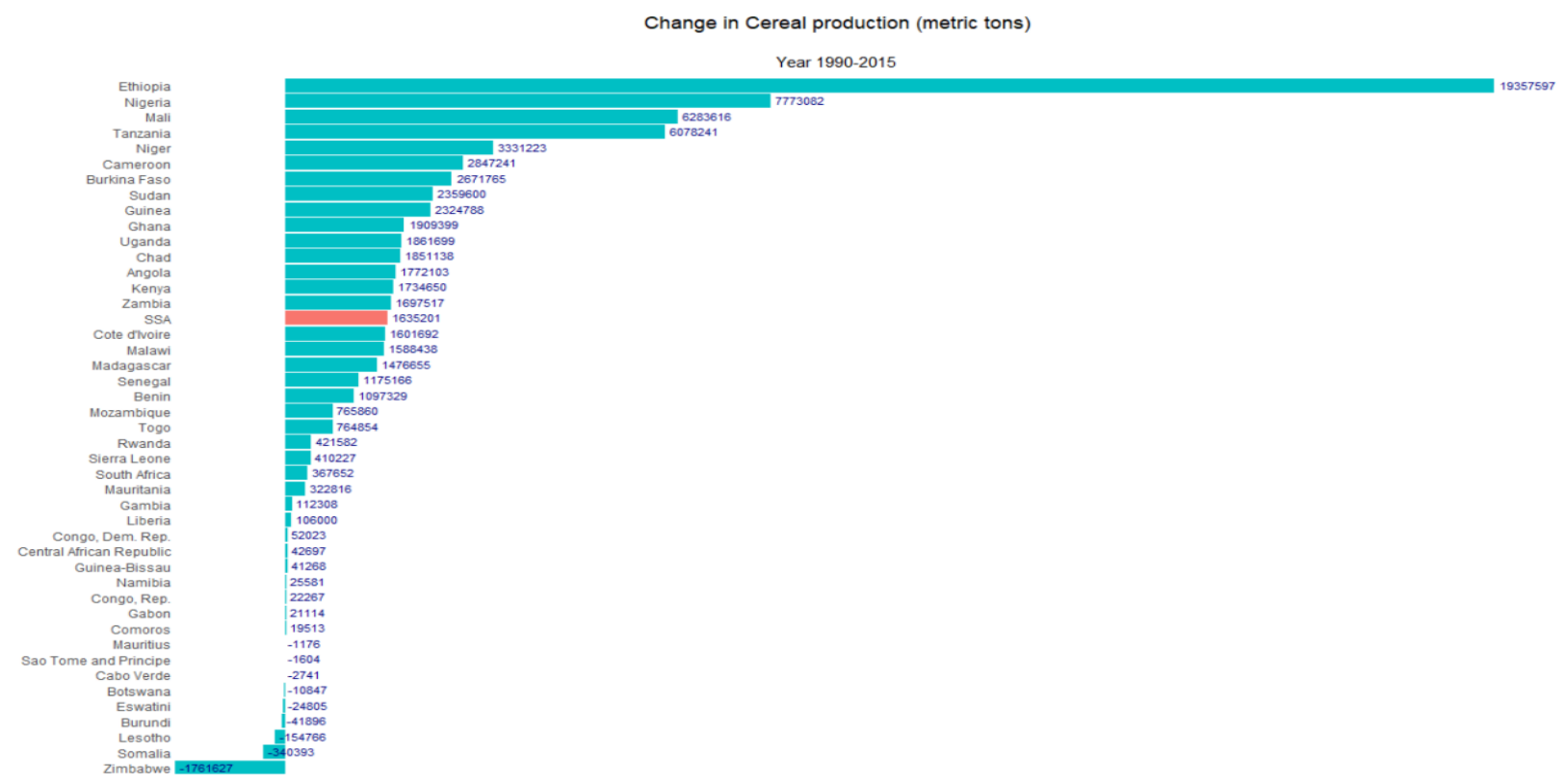

Figure 9: Changes in Cereal Production in Metric Tons for SSA: 1990 and 2015

\section{Discussion}

The agricultural potentials, especially for cereal crops production amongst many other types of seasonal crops, are enormous and not properly or fully exploited in SSA. Previous studies (Matusso et al., 2014; Wassmann et al., 2009; Tadesse et al., 2008), propose that SSA could become a future world breadbasket if its potentials and resources are well tapped. Well, arguments on this ground are based on the fact that most of the existing SSA cereal cropland receive sufficient precipitation ( $>900 \mathrm{~mm}$ per year), equal to or greater than all existing breadbaskets in the world except for the humid tropical areas in Asia (Hengsdijk \& langeveld, 2009). Progress in productivity and the yield gap, (variations in the potential of crop yields based on theoretical knowledge of relevant agro-ecological production processes and the yields as obtained by farmers in practice) have been the subject of debate (Lal, 2015). Cereal yield gap has been challenged by some significant production constraints such as limited water availability; limited nutrient availability; inadequate crop protection; insufficient or improper use of labor or mechanization, and; a considerable knowledge gap (Goergen et al., 2016).

Considerably, there has been an increase in average cereal yield and production levels over the years, and this is associated with an average increase in land area under cereal production in SSA. About $71 \%$ of the countries in SSA are experiencing a continuous increase in cereal yield, production levels and land area under cereal production, while about
$29 \%$ are experiencing a reduction in cereal yield, production levels and land area under cereal production. There is a forecast that SSA is one of the regions in the world that is highly dependent on cereal imports and with its cereal self-sufficiency to fall further to about $54 \%$ by 2050 (Thome et al., 2018). Thus, there is a need to increase the land area devoted to cereal production as well as cereal productivity. The findings show that land area under cereal production in SSA increased to 679664 (14\%) hectares in SSA in the year 2015. However, a continuous increase in the land area under cereal production is an indication that production per unit area is still meagre, since, SSA is one of the regions with the least application of modern science in agriculture and poor sustainable intensification in farming systems. Hence future demands of cereals from SSA have to be met under conditions of decreasing or prevailing land area with increasing productivity. This is the case with South Africa, which is currently experiencing a reduction in the land area under cereal production with a tremendous increase in the amount of cereal yield per hectare. There is more demand for arable land for other purposes such as infrastructure, housing, and meeting of needs of the growing population.

Maximum yield potentials can be realized if farmers can have access to knowledge and technological capabilities in their use of farm inputs such as fertilizers, pesticides, water, seeds, nutrients, and land irrigation. Key production constraints such as poor soil quality, lack of water and nutrients in SSA (Conway \& Schipper, 2011) continue to limit yield increase in the sub-continent. Putting in place 
adequate infrastructures and phytosanitary procedures for the management and control of pests and diseases is very instrumental in the region to sustain and improve yield levels. However, with a changing climate, emerging pest such as the fall armyworm is a potential threat to cereal production in the region, and the resources to manage outbreaks are often very limited in the region (Reardon et al., 1994). Although there is a significant presence of international research organizations in the region such as the International Institute of Tropical Agriculture - IITA, Forum for Agricultural Research in Africa - FARA, Africa Rice Centre, SSA's cereal yield is still insufficient to meet up with its current population. Other donor led programs such as the Green Revolution and with constant support from a donor like the World Food Program are all working together to improve farming systems and meeting the demand from its increasing population. The present study shows that on average cereal yield in SSA increased by $17 \%$ from 1109 kilograms per hectare in the year 1990 to 1420 kilograms per hectare in the year 2015.

Nevertheless, SSA's agriculture is still experiencing the slowest record of productivity increase in the world (Sinclair \& Rufty, 2012), with cereal producer's attainable yield far below the expected yield in SSA. While population growth remains on the rise with an exponential increase of 800 million in 2000 to a projected 1.8 billion by 2050 (Van Oort et al., 2015), there is a need to step up farmers' attainable yield levels to an actual or reasonable yield level. Another major constraint is available farm credit and adequate government/policy support. With little or no incentives to assist farmers to invest in productivity-enhancing technologies, cereals yield continue to increase at a plodding pace compared to the food insecurity growth rate caused by the rapid population growth rate in SSA. With over 35.5 percent of its population currently food insecure and projections that it will stay at 24 percent by 2028 (FAO, WFP \& IFAD, 2012), that gives an urgent need to foster cereal output per unit area. This is because cereal is a major staple crop in SSA, and an increase in cereal yield can significantly reduce the food insecurity challenges in the region.

The rapidly growing population, increase in food demand, increased urbanization and producing sufficient staple food crops have also been identified as a major challenge for SSA (Boyd et al., 2013) and therefore a need to be treated with urgency although the findings show that average cereal output in SSA increased from 1603912 metric tons in 1990 to 3239113 metric tons in the year 2015. However, SSA is still the largest food-insecure region in the world posing a threat to $35.5 \%$ of its population, and it is projected that, by $2028,24 \%$ of its people will still be food insecure (FAO, WFP \& IFAD, 2012) raising a need to step up its production levels. Cereal remains a predominant staple food for the people of SSA. Most of their diets constitute a significant portion of cereals, thus showing its relevance. However, with the rising threats from climatic changes, emerging and new pests and diseases, amongst other socio-political constraints, much still needs to be done in the region to meet the demand for its population. Governments need to be more proactive and invest more in the sector and prioritize the food and nutrition needs of their population.

\section{Conclusions}

Cereal yield, production level and land area under production have witnessed significant progress in SSA between 1990 - 2015. However, SSA still has the lowest yield trends, minimal investment in technological advancements with the highest number of food-insecure persons that are forecast to exacerbate further owing to its growing population. These are all major constraints to sustainable livelihood for Sub-Saharan Africans. With such a scenario, there is a need to step up cereal production and yield levels in the region through innovative research, training, introducing irrigation systems, and providing incentives and access to feasible credit/loan schemes to producers that will encourage production. Limiting factors such as water availability, insufficient crop protection, and inadequate use of labour and lack of mechanization which are also fundamental causes to the slow growth in cereal production in SSA and have to be addressed through the formulation and implementation of adequate policies. However, through research and development efforts by various international and local research institutes, progress is been made in the region to address some of these challenges. The involvement of youths in farming and agri-business from internationally led donor support programs are transforming the agricultural sector in the region and showcasing its potentials. Also, governments are supposed to be more pro-active in supporting local initiatives that promote cereal production through the formulation of feasible policies.

\section{Authors' Contribution}

Author Ghose Bishwajit conceptualized the study, collected and analyzed the data; Richard A Nyiawung and Neville Suh performed the interpretations, literature searches, drafting and revisions. All authors read and approved the final manuscript.

\section{Acknowledgements}

We truly acknowledge and appreciate the provision of the datasets by the World Bank. 


\section{References}

Baulcombe, D., Crute, I., Davies, B., Dunwell, J., Gale, M., Jones, J., \& Toulmin, C., 2009. Reaping the benefits: Science and the sustainable intensification of global agriculture. The Royal Society.

Bourne, J.K., 2019. The Next Breadbasket. National Geohraphic Magazine. n.d. Accessed 20 June 2019. Available: https://www.nationalgeographic.com/foodfeatur es/land-grab/

Boyd, E., Cornforth, R.J., Lamb, P.J., Tarhule, A., Lélé, M.I., Brouder, A., 2013. Building resilience to face recurring environmental crisis in African Sahel. Nature Climate Change, 3(7), 631.

Collier, P., Dercon, S., 2014. African agriculture in 50 years: smallholders in a rapidly changing world? World development, 63, 92-101.

Conway, D., Schipper, E.L.F., 2011. Adaptation to climate change in Africa: Challenges and opportunities identified from Ethiopia. Global Environmental Change, 21(1), 227-237.

Diao, X., Hazell, P., Thurlow, J., 2010. The role of agriculture in African development. 2010. World development, 38(10), 1375-1383.

Dinar, A., Hassan, R., Mendelsohn, R., \& Benhin, J., 2012. Climate change and agriculture in Africa: impact assessment and adaptation strategies. 2012. Routledge.

FAO, 2010. The Special Challenge for Sub-Saharan Africa. Accessed 29 May 2019. Available: http://www.fao.org/fileadmin/templates/wsfs/d ocs/Issues_papers/HLEF2050_Africa.pdf

FAO, WFP and IFAD, 2012. The State of Food Insecurity in the World 2012. Economic growth is necessary but not sufficient to accelerate reduction of hunger and malnutrition. Rome, FAO. 2012 Available: http://www.fao.org/3/a-i3027e.pdf

Goergen, G., Kumar, P.L., Sankung, S.B., Togola, A., Tamò, M., 2016. First report of outbreaks of the fall armyworm Spodoptera frugiperda (JE Smith) (Lepidoptera, Noctuidae), a new alien invasive pest in West and Central Africa. PloS one, 11(10), $\mathrm{e} 0165632$.

Hengsdijk, H., Langeveld, J.W.A., 2009. Yield trends and yield gap analysis of major crops in the world (No. 170). Wettelijke Onderzoekstaken Natuur \& Milieu.

Jayne, T.S., Rashid, S., 2013. Input subsidy programs in Sub-Saharan Africa: a synthesis of recent evidence. Agricultural economics, 44(6), 547-562.
Lal, R., 2015. Sustainable intensification for adaptation and mitigation of climate change and advancement of food security in Africa. In sustainable intensification to advance food security and enhance climate resilience in Africa (pp. 3-17). Springer, Cham.

Matusso, J.M.M., Mugwe, J. N., Mucheru-Muna, M., 2014. Potential role of cereal-legume intercropping systems in integrated soil fertility management in smallholder farming systems of Sub-Saharan Africa. Research Journal of Agriculture and Environmental Management, 3(3), 162-174.

McIntyre, B.D., 2009. International assessment of agricultural knowledge, science and technology for development (IAASTD): Global Report.

Reardon, T., Crawford, E., \& Kelly, V., 1994. Links between nonfarm income and farm investment in African households: Adding the capital market perspective. American journal of agricultural economics, 76(5), 1172-1176.

Sanchez, P.A., Denning, G.L., Nziguheba, G., 2009. The African green revolution moves forward. 2009. Food Security, 1(1), 37-44.

Shah, M., Fischer, G., van Velthuizen, H., 2008. Food security and sustainable agriculture. The challenges of climate change in Sub-Saharan Africa. International Institute for Applied Systems Analysis, Laxenburg.

Sinclair, T.R., Rufty, T.W., 2012. Nitrogen and water resources commonly limit crop yield increases, not necessarily plant genetics. Global Food Security, 1(2), 94-98.

Spielman, D. J., Pandya-Lorch, R., Eds., 2009. Millions fed: Proven successes in agricultural development.. Intl Food Policy Res Inst.

Tadesse, T., Haile, M., Senay, G., Wardlow, B.D., Knutson, C.L., 2008. The need for integration of drought monitoring tools for proactive food security management in Sub-Saharan Africa. In Natural resources forum (Vol. 32, No. 4, pp. 265-279). Oxford, UK: Blackwell Publishing Ltd.

Thome, K., Birgit, M., Kamron, D., Cheryl, C., 2018. International food security assessment, 2018-2028. GFA-29, U.S. Department of Agriculture, Economic Research Service. 2018. Accessed 1 May 2019.2 Available: https://www.ers.usda.gov/publications/pubdetails $/$ ?pubid $=89390$

Tongruksawattana, S., Wainaina, P., 2019. Climate shock adaptation for Kenyan maize-legume farmers: choice, complementarities and 
substitutions between strategies. Climate and Development, 1-13.

UNDESA, 2013. World population prospects: the 2012 revision, key finding and advance tables. 2013. Working paper No. ESA/P/WP 227. United Nations, New York. 2013. Accessed 16 April 2019.

Available: http://esa.un.org/wpp/Documentation/pdf/WPP 2012_\%20KEY\%20FINDINGS.pdf.

USDA, 2010. United States department of agriculture -. Food security assessment, $2010-20$. Indicators in 2010 for many lower-income countries due in part to economic recovery. Accessed 20 June 2019.Available:https://www.ers.usda.gov/webdoc s/publications/37229/13462_gfa21_1_.pdf?v=0

Van Oort, P.A.J., Saito, K., Tanaka, A., AmovinAssagba, E., Van Bussel, L.G.J., Van Wart, J., Wopereis, M.C.S., 2015. Assessment of rice self- sufficiency in 2025 in eight African countries. Global Food Security, 5, 39-49.

Ward, P.S., Florax, R.J., Flores-Lagunes, A., 2013. Climate change and agricultural productivity in Sub-Saharan Africa: a spatial sample selection model. European Review of Agricultural Economics, 41(2), 199-226.

Wassmann, R., Jagadish, S.V.K., Sumfleth, K., Pathak, H., Howell, G., Ismail, A., Serraj, R., Redona, E., Singh, R.K., Heuer, S., 2009. Regional vulnerability of climate change impacts on Asian rice production and scope for adaptation. Advances in Agronomy, 102, 91-133.

World Bank, 2008. World development report 2008: Agriculture for development. Washington, DC. (C) World Bank. 2007. https://openknowledge.worldbank.org/handle/109 86/5990 License: CC BY 3.0 IGO. 